\title{
LA NOVELA COMO RETRATO: EL ARTE DE FRANCISCO DELICADO
}

En torno al Retrato de la Lozana andaluza de Francisco Delicado hay una verdadera conspiración de silencio. Como en tantos otros casos de obras olvidadas por razones morales, el responsable de ello es Menéndez Pelayo. En los Orígenes de la novela ${ }^{1}$ se muestra escandalizado por la obscenidad de la Lozana, y da a entender que sólo sú sentido del deber como historiador de la literatura lo ha decidido a abrir tan inmundo libro ${ }^{2}$. La crítica de Menéndez Pelayo es, a su vez, escandalosa por su exagerado puritanismo; se concreta a juicios morales y a una expresión de alivio porque, al fin y al cabo, la Lozana andaluza es un fenómeno aislado en las letras españolas ${ }^{3}$ : no debe casi nada a la Celestina e influye poco en el Lazarillo de Tormes y en la tradición picaresca. En resumen, hay que huir de ella como de un apestado ${ }^{4}$.

Nadie, desde entonces, se ha atrevido a desafiar el anatema lanzado por el gran crítico sobre los lectores de esta obra. Los autores de manuales se limitan a presentarla como una novela vergonzosa, o -en palabras de Mérimée-Morley- como "un excelente texto lingüístico, pero no apto para estudiantes jóvenes"”.

Todo eso hace que nos acerquemos a la Lozana andaluza con

${ }^{1} N B A E$, vol. XIV, págs. cLxxxviII y sigs.

${ }^{2}$ Ibid., pág. Cxcrv: "Digamos algo de la Lozana andaluza, sin entrar, por supuesto, en su análisis, que no es tarea para ningún crítico decente. La Lozana, en la mayor parte de sus capítulos, es un libro inmundo y feo..."

${ }^{3}$ Ibid., pág. CcII: "El Retrato de la Lozana es una producción aislada, que ninguna influencia ejerció en nuestra literatura ni en la italiana, aunque se haya pretendido lo contrario... Por otra parte, el género a que pertenecía, y que de ningún modo ha de confundirse con las Celestinas, era exótico para nosotros". Y pág. cxcvi: "La Lozana no tiene antecedentes literarios". Sólo una edición del siglo xvi ha llegado a nuestros días.

"Ibid., pág. car: "su lectura no puede recomendarse a nadie".

${ }^{5}$ A history of Spanish literature, New York, 1930, pág. 204. Hay que reconocer que Valbuena Prat (Historia de la literalura española, $1^{\text {" ed., Barcelona, }}$ 1937, vol. I, pág. 356) no se guía, en su apreciación de la Lozana, por prejuicios ni reservas morales: "una gran riqueza expresiva con multitud de influencias... se une con un sentido de observación de costumbres y una graciosa vivacidad y alegría del vivir que nos coloca frente a una obra típica de Renacimiento italianizante". 
cierta sensación de acometer lo vedado. El texto nos es asequible gracias a la diligencia de Fuensanta del Valle (1871), Rodríguez Serra (1899), E. M. de Segovia (1916) y otros editores; pues si la tajante condena de Menénde $\%$ Pelayo ha impedido la publicación de monografías, no escasean, en cambio, las reediciones modernas. La sensación pecaminosa se desvanece pronto: no tardamos en sentir que nos hallamos frente a una obra de ardua lectura, y que el esfuerzo por vencer las dificultades vale la pena. Comprendemos entonces que la Lozana andaluza no es una simple retahila de escenas pornográficas, sino una gran obra de arte injustamente olvidada. Tenga o no un lugar en la tradición de la picaresca española, posee por sí sola un título a la atención del hispanista.

¿Qué cosa movió a Francisco Delicado a escribir su libro? Él mismo lo explica en los preliminares. No es mera casualidad que emplee la palabra "retrato" en el título. Ha pintado un retrato en condiciones difíciles y con materiales difíciles. Su propósito primero ha sido retratar, con palabras y no con colores, a una mujer conocida de él, cuya existencia y modo de vida son significativos para quienes desean comprender el ambiente y el momento histórico en que ella vivió. Así como un buen pintor se esfuerza por poner en su cuadro algo más que los rasgos físicos de la persona a quien retrata, y ve hacia adentro - la psique- y hacia afuera - el fondo-, así este retratista que pinta con palabras se esforzará por explicar las acciones de acuerdo con el talento natural -el "ingenio"- de su heroína, y de acuerdo con su medio, la Roma de los años que preceden al gran Saco. La dificultad de la tarea se acrecienta por el hecho de que la persona retratada no se está quieta en una silla: el autor necesita observar cómo se mueve por las calles de su ciudad adoptiva, y para retratarla necesita él mismo caminar con ella, tomando notas sobre todo cuanto mira.

Delicado se encuentra ante el mismo dilema que el pintor: retratar fielmente, o adular al sujeto; y decide ser artista verídico, dejar que la verdad sea su principio guiador. "Solamente diré lo que oý y vi", declara (pág. 1); "retraxe lo que vi que se devría retraer" (pág. 3). Ninguna de las cosas significativas que ha visto alrededor de Lozana quedará fuera de su cuadro. El artista, en esas ocasiones, suele ser objeto de la ociosa curiosidad de la gente, y tiende a sentirse cohibido cuando camina por las calles de una ciudad familiar con su paleta y sus pinceles en la mano. Inhibiciones de esta clase las sufrió también Delicado, que confiesa haber desaprovechado, por esa causa, algunas buenas oportunidades. Cuando lo invitan a una especie de

6 Las ediciones más modernas son las de Javier Farías (Buenos Aires, 1942), la facsimilar de A. Pérez Gómez (Valencia, 1951) y la de A. Vilanova (Barcelona, 1952); a esta última remitirán nuestras citas. 
salón de belleza donde está Lozana, él rehusa por timidez: "No quiero yr porque dizen después que no hago sino mirar y notar lo que passa, para screvir después, y que saco dechados" (pág. 68).

La idea de componer un retrato literario le ha venido de Juvenal, cuyo ejemplo le sirve además de excusa para la cruda sinceridad de su cuadro. Juvenal escribió lo que en sus tiempos pasaba; él hace otro tanto; no es, pues, más censurable que el poeta latino (págs. 1-2). Esta referencia a Juvenal es una clave para la interpretación del retrato de Lozana. Juvenal zahirió despiadadamente las torpezas de la Roma del siglo r. También Delicado, al pintar como fondo de su cuadro la Roma de antes de 1527 , pone a su heroína en medio de una sociedad dominada por el vicio y la corrupción. Al retratar a una mujer en Roma, procede de lo particular a lo general: "quise retraer munchas cosas retraiendo una" (pág. 3); "por lo poco entiendan lo muncho" (pág. 4). Así también Juvenal, al trazar los rasgos de unos pocos ciudadanos, había logrado ofrecer un panorama de los vicios de toda Roma. Delicado nos dice que hace un "retrato sacado del Jure cevil natural", esto es, una especie de elaboración de un expediente sacado del registro civil de Roma, o de la naturaleza. Pero lo que hubiera podido ser simplemente ese seco expediente se transforma en un fragmento de historia palpitante de vida. La naturaleza está presente en su libro, pero es la naturaleza tal como se encuentra en una ciudad. Roma ha transpuesto la vida natural a una clave distinta, y ésta es la clave que emplea Delicado cuando se decide a "mezclar natura con bemol"7.

Es, pues, un libro agridulce. Lleno de la alegría y vitalidad de la Italia del Renacimiento, está sin embargo coloreado de tristeza, matizado por un sentimiento de pecado y un presagio de la ruina inminente. La mayoría de los autores - medievales, renacentistas o barrocos- declaran que su propósito es entretener, instruir o una y otra cosa: "deleitar aprovechando". Delicado expresa su intención de manera distinta: "daré olvido al dolor" (pág. 2). Quienes van a leer su libro (publicado en Venecia en 1528) están de luto: son refugiados españoles que han huído de la ira de los romanos y que se han cubierto -metafóricamente- de cilicio y ceniza por el Saco de Roma, por la podredumbre que los rodea, por su responsabilidad en el desastre. En su Diálogo de las cosas ocurridas en Roma, Alfonso de Valdés demostró, para satisfacción de la cristiandad entera, aunque no quizá de los ciudadanos romanos, que el Saco no se había

7 Pág. 2; la frase se aclara por el contexto: "Y assí vi que mi yntención fué mezclar natura con bemol, pues los santos ombres, por más saber, y otras vezes por desenojarse, léan libros fabulosos y cogían entre las flores las mejores”. RAFAfI A. SuÁkez, “Metáforas musicales en el idioma castellano", MLJ, XXXIII, 1949, págs. 179-184, estudia la palabra bemol sólo en el sentido de 'dificultad'. 
debido a un error de su señor Carlos $\mathrm{V}$, sino a un providencial castigo contra los corrompidos habitantes de esa moderna Gomorra ${ }^{8}$. Los afligidos desterrados de la ciudad santa hallarán en el libro de Francisco Delicado algo que los saque de sus tristezas y de sus sentimientos de culpabilidad. El autor adormecerá sus recuerdos con un relato de los ingredientes amenos, aunque pecaminosos, de ese pasado que lloran: va a "traer a la memoria munchas cosas que en nuestros tienpos passan, que no son laude a los presentes ni espejo a los a venir" (pág. 2). Delicado no tiene ningún afán moralizador. Admite con toda franqueza que su obra es escandalosa, pero afirma que hace falta esa carga de escándalo para ayudar a los hombres a olvidar.

Así, escoge dos grandes temas escandalosos y los funde en un retrato de lo particular, para que de él se deduzca lo general de la corrupción. En la despreocupada pecaminosidad de su heroína está el pecado de todos los hombres, y en los pecados de Roma están los del mundo. Sus dos temas son el amor sexual y la eterna prostitución de Roma.

El autor tiene, pues, un propósito bien definido. Es un artista consciente, un retratista que trabaja con palabras. Como relata lo que oyó (y no sólo lo que vió), intenta, por primera vez en español, reproducir a lo largo de su obra el habla de la gente de la calle ${ }^{9}$. En la Celestina, su más inmediato predecesor en ese sentido, no se emplea el picante diálogo popular sino en algunas ocasionales charlas de Celestina con otras personas de su medio. El propósito expreso de Delicado es reproducir la naturaleza; aunque transpuesta a otra clave, y el lenguaje natural es parte de su concepto de la naturaleza. Resuelve, en consecuencia, desechar los recursos de la retórica; no pretende imitar a ningún escritor anterior (Juvenal le ha servido sólo como punto de arranque), sino transcribir fielmente la vulgaridad del habla cotidiana. Su credo artístico es la verdad, no la belleza. Así, este Céline del siglo xvi escribe: "Protesta el autor que ninguno quite ni añada palabra ni razón ni lenguaje, porque aquí no conpuse modo de hermoso dezir, ni saqué de otros libros, ni hurté eloqüencia, porque para dezir la verdad poca eloqüencia basta, como dize Séneca" (pág. 3). Y en efecto, mucho más que en la Celestina o el Lazarillo, se observa en la Lozana andaluza un abuso de la conjunción y, del

s En cierto momento, Lactancio pregunta al Arcediano: “¿Dónde se hallaron más vicios, ni aun tantos, ni tan públicos, ni tan sin castigo como en aquella corte romana?" Y más tarde: "Como vosotros no quesistes oír las honestas reprehensiones de Erasmo, ni menos las desonestas injurias de Luter, busca Dios otra manera para convertiros, y permitió que los soldados que saquearon a Roma con don Hugo y los coloneses, hiziessen aquel insulto de que vos os quexáis" (ed. J. F. Montesinos, 1928, págs. 124 y 143).

${ }^{9}$ Cf. Menéndez Pelayo, op. cit., págs. Cxciv-cxcv: "La Lozana no está escrita, sino hablada". 
lenguaje coloquial, de neologismos, de palabras gruesas. El autor reconoce, claro está, que no puede reflejar con absoluta fidelidad el modo de hablar de Lozana; confiesa que se ve obligado a mezclar su naturaleza con bemoles, a falsear un poco el cuadro: "por esso verná en fábula muncho más sabia la Loçana que no mostrava" (pág. 4). Pero no lo arredra la dificultad de la tarea. Delicado ha oído hablar italiano en las calles de Roma, y así sus personajes - ciento veinticinco en total- emplean a menudo esa lengua. Los barceloneses hablan a veces catalán; un portugués se expresa en una jerga chapurrada de portugués y castellano, y los residentes españoles de Roma se sirven de un español italianizado. Como estos últimos son la mayoría, la novela es rica mina de italianismos; pocos ejemplos bastarán para tener una idea: "se fueron en Levante" (pág. 15); "veramente" (pág. 13); "madona Loçana" (pág. 17); qualque por 'alguno' (passim); la conjugación del verbo estar con el auxiliar ser ("es estada mundaria toda su vida", pág. 21); el uso del futuro de indicativo después de cuando ("¿qué hará de sus pares ella quando parirá?”, pág. 103); fin a por 'hasta' ("me desnudó fin a la camisa", pág. 27). En un lenguaje tan vulgar desentonarían las palabras cultas; aparecen sólo muy de vez en cuando, y entonces dan lugar a comentarios. Después de oír una enumeración de los diversos tipos de prostitutas que hay en Roma, Lozana observa: "Señor, essas putas reyteradas me parecen", a lo cual replica sarcásticamente su compañero: "Señora, ¿y latín sabéys? Reytero, reyteras, por tornároslo a hazer otra vez" (pág. 85). Aunque ajeno al afán de buscar efectos artísticos, Delicado emplea hábilmente las palabras, con la habilidad del hombre de la calle: "hay putas buenas y putas malas y malas putas" (pág. 84). Aquí, el paso del juicio moral - "putas malas" - a la censura de las putas desmañadas - "malas putas"- se hace con notable economía de palabras. Hay en el estilo de Francisco Delicado un rasgo - la similicadenciaque parece erudito; pero, como observa con justeza Menéndez Pidal a propósito del mismo fenómeno en fray Antonio de Guevara, es éste un reflejo de la lengua hablada, no un artificio de estilo ${ }^{10}$. Vemos confirmada esta conjetura en un pasaje de la Lozana andaluza; dice Ulixes: "Esso de pellejar que me plaze; pellejedes, pellejón, pelléjame este cojón”; y Lozana comenta: "Bivas y adivas, sienpre coplica" (pág. 128). En otras palabras, Ulixes no puede menos de hacer coplas o rimas al hablar.

El estilo de la Lozana andaluza refuerza, pues, el propósito que el autor tiene de reproducir su observación de Lozana en una pintura hecha con palabras. A falta de término mejor, podemos dar a ese propósito el tan trillado nombre de "realismo". Este realismo de Deli-

10 "El lenguaje del siglo xvi", en Los romances de América, Buenos Aires, 1939, pág. 159 . 
cado tiene dos aspectos: en primer lugar, la falta de trabas en la observación (la realidad no se ve, como en Cervantes, a través de un prisma, sino a través de un telescopio), y en segundo lugar la observación de la falta de trabas sociales (los hombres y las mujeres se aceptan unos a otros sin inhibiciones, sin tratar de meter su conducta en la horma de las convenciones). El retrato de Lozana y de su círculo presenta sin titubeos las crudezas de la vida, consecuente con la ausencia de titubeos en las relaciones de enamorados, de personajes lascivos y de gente que lucha por ganarse la vida. $\mathrm{El}$ autor nos dice unas palabras acerca de su técnica realista. Se siente orgulloso de los resultados: "este Retrato es tan natural, que no ay persona que aya conoscido la señora Loçana en Roma, o fuera de Roma, que no vea claro ser sacado de sus actos y meneos y palabras" (pág. 4). La tarea del retratista se complica por la movilidad del modelo. Pero, en el sentido más estricto, Lozana es el modelo, el dechado: "Yo he trabajado -dice Delicado hablando de sus relaciones con la andaluza- de no escrevir cosa que primero no sacasse en mi dechado la labor, mirando en ella o a ella" (ibid). Es decir, que su busca del realismo es algo más que simple fidelidad fotográfica; ha completado la observación de los rasgos exteriores de su modelo - a ella- con una introspección de su psique - en ella. Ahora bien, esta doble observación no podía ser objetiva; tenía que pasar por las facultades discriminadoras del espíritu del artista: "sacava lo que podía, para reduzir a memoria" (ibid.). Mientras las observaciones fermentaban en su memoria, su propia personalidad -actitudes, juicios, comprensión artística- iba dejando en ellas su carácter. De este modo, casi imperceptiblemente y sin asomo de didacticismo, la imagen queda sujeta a una interpretación y colocada en un ambiente significativo.

Delicado tiene la confianza de todo verdadero artista en su facultad discriminadora, en su derecho de elegir y rechazar. Lo mismo que los pintores, aspira en su obra a una especie de perfección, y la logra. Nadie será capaz de mejorar su retrato: él ha hecho cuanto podía; los demás no llegarán a tener la misma visión que él: "porque no le pude dar mejor matiz, no quiero que ninguno añada ni quite" (pág. 4). Ha logrado una perfección relativa; sus matices -él mismo emplea este tecnicismo pictórico- son los que debían ser. Piensa en su actividad creadora como en una lucha con sus materiales. Ni la pintura ni las palabras pueden representar fielmente la naturaleza ${ }^{11}$; por eso, en cierto modo, su esfuerzo no es del todo satisfactorio. Es per-

11 Sin embargo, siempre pueden hacerse en una pintura retoques especiales para satisfacer a una crítica justa. Los artistas de la palabra no pueden beneficiarse en esa forma de la crítica, puesto que, al publicarse, la obra queda fijada en forma definitiva: "despućs de aver cortado la materia y dádole forma, no pueden sin pérdida emendar” (pág. 4). 
fecto sólo en el sentido de que nadie pudo haberlo hecho mejor: "y viendo vi muncho mejor que yo ni otro podrá escrevir" (ibid.).

El otro aspecto de su realismo - pintura de relaciones en que no hay la menor inhibición moral- puede apreciarse muy fácilmente. Para sus personajes, el amor es una mercancía que puede comprarse y venderse, pero también una fuente de placer sin trabas. En su concepto de la vida (cuyo centro es el acto amoroso) no hay lugar para vacilaciones ni modestias. "Señora mía - dice Lozana sin rodeos a una señora napolitana-, ¿son donzellas estas vuestras hijas?" La respuesta no se hace esperar: "Son y no son, sería largo de contar" (pág. 34). No es que la buena mujer trate de zafarse ante una pregunta demasiado indiscreta; simplemente, no quiere aburrir con su historia. Los personajes de la Lozana andaluza nunca emplean las expresiones convencionales de cortesía o moralidad; viven en un mundo del todo amoral. El deseo de placer sin trabas y la posesión de ese placer destierran todo escrúpulo. Cuando Lozana se encuentra por primera vez con el adolescente Rampín y deja que se acueste en su cama, comienza por fingir recato y dice que tiene marido, a lo cual contesta Rampín con toda sencillez: "Pues no está agora aquí para que nos vea" (pág. 51). La escena que a esto sigue está hecha con un naturalismo de lenguaje absolutamente único en la novela española.

También es único el concepto que tienen del amor todos los personajes de la Lozana andaluza. No es el amor cortesano de la Cárcel de amor, ni la idea neoplatónica de la Diana, ni siquiera el concepto ovidiano del Libro de buen amor, que es el que más se le parece. El amor ovidiano difiere del de la Lozana andaluza en que insiste en los preliminares del amor: la seducción por medio de regalos, el papel de la alcahueta, la progresiva conquista de la mujer, etc. En la novela de Delicado, el acto amoroso no tiene preludios; los favores extremos se conceden siempre con sólo que se pidan. Las mujeres se muestran tan dispuestas a la conquista amorosa como los hombres. Contando a unas sevillanas su primera infancia, Lozana les dice: "Desde chiquita me comía lo mío, y en ver ombre se me desperezava, y me quisiera yr con alguno, sino que no me lo dava la hedad" (pág. 22). El centro de este código sin rodeos del amor es el acto sexual, no los actos precedentes, concomitantes o subsiguientes. Así, Lozana dice a Diomedes, su primer amante: "No pienso en hijos ni en otra cosa que dé fin a mi esperanza, sino en vos" (pág. 16). Dentro de tal sistema, el matrimonio carece de importancia. Lozana tiene ya varios hijos de Diomedes, cuando un día él le dice casualmente: "Allí [en España] me entiendo casar con vos", proposición poco romántica, por cierto. Es el suyo una especie de matrimonio por contrato; a Diomedes le gusta la mercancía que ha comprado, y desea conservarla.

Cosa curiosa, el amor de este tipo, basado casi exclusivamente 
en las necesidades y apetitos físicos, no es ni egoísta ni falto de blandura. Incluye, como por accidente, ciertas cualidades morales. Esta abierta sexualidad, tal como la retrata Delicado, da lugar a un respeto mutuo entre los amantes. Los crueles, en la Lozana andaluza, son los que no tienen el impulso de un interés sexual: el padre de Diomedes, por ejemplo, que desaprueba los amores de su hijo y ordena despojar a Lozana de cuanto tiene y echarla al mar. Como el amor es puramente sexual por naturaleza, carece de todo elemento moral, como la fidelidad o la monogamia. Diomedes mismo se siente orgulloso de que sus amigos contemplen a Lozana con ojos codiciosos. Y cuando la abandona para volver a casa de su padre, expresa en términos significativamente dudosos la esperanza de mutua fidelidad: "Suplicóla que se esforçasse a no dexarlo por otro ombre, que él se esforçaría a no tomar otra por muger que a ella" (pág. 15). Delicado ve en el amor una pasión no refrenada por intenciones morales, una necesidad a la que no hay manera de resistir. El hombre es frágil, la mujer es frágil; el amor es infinitamente más poderoso.

Pero el amor no es sólo una pasión desenfrenada, sino también una pasión primaria. Los caracteres secundarios del acto erótico, los temas de la pornografía, no tienen cabida en la Lozana andaluza. No hay en ella exhibiciones obscenas. Las novelas sentimentales, con sus amores jamás recompensados, o el Tirant lo Blanch, en que Carmesina ofrece y niega sucesivamente los favores extremos a su enamorado, son, en este sentido, obras más pornográficas que la Lozana. El amor que procede con ambages no le inspira sino desprecio. En una graciosa parodia de los amores novelescos convencionales, Diomedes dice en tono festivo: “Ay! ¡ay! iqué herida! Que de vuestra parte qualque vuestro servidor me a dado en el coraçón con una saeta dorada de amor". Lozana continúa el hilo de la parodia: "No se maraville vuestra merced, que quando me llamó que viniese abaxo, me parece que vi un mochacho, atado un paño por la frente, y me tiró no sé con qué". Y luego, con seis palabritas muy bien puestas, desinfla tan pomposa retórica: "en la teta yzquierda me tocó" (pág. 12).

En la Lozana andaluza el cortejo amoroso se hace sin rodeos ni cumplidos: es un negocio como cualquier otro. El mercader dice a la tía de Lozana: "Yo querría ver aquella vuestra sobrina. Y por mi vida que será su ventura, y vos no perderéys nada" (pág. 11). El autor destruye siempre el menor intento de un personaje por ennoblecer las negociaciones del amor. Así, en este mismo episodio, la tía dice al mercader que su sobrina está "mal aliñada" y no puede bajar a verle, pero le ofrece en cambio mostrarle en el telar unas labores suyas, a lo cual el mercader, rechazando bruscamente el subterfugio, replica: "Señora mía, pues sea luego" (pág. 12). Los rega- 
teos de la vieja no surten efecto, y la joven Aldonza tiene que bajar en seguida a que el mercader le dé su visto bueno.

También se descarta en la Lozana andaluza la tradicional distinción entre loco amor y buen amor. El amor no es tema de juicios morales, no puede ser bueno o malo. Delicado no distingue más que entre chambonería y habilidad en el acto amoroso. Nada de juicio moral; sólo criterio práctico. Si los favores de Lozana gozan de mucha demanda, es por aquello que Delicado llama su "arte muy sagaz" (pág. 1). Lozana es una amante de habilidad consumada.

Cabe preguntar ahora qué clase de mujer es ésta que ha elevado el amor al nivel de un arte. La novela nos dice que su verdadero nombre es Aldonza, que tuvo dos hermanas, que acompañó a su madre en viajes por toda España. La madre le enseñó a "texer, ... hordir y tramar" (págs. 7-8), de tal suerte que nunca llegó a olvidar este arte. Al quedar huérfana, se va a vivir con una tía, que le enseña a manejar a los hombres. La tía le predice que será muy feliz: "Hija, sed buena, que ventura no's faltará" (pág. 8). En algún lugar, Aldonza aprende a leer la palma de la mano y a hablar catalán.

Con tan modesto bagaje y con su natural "ingenio", se va abriendo camino en el mundo. Su buen éxito se debe sobre todo a su sistemática técnica mercantil. Como un comerciante viajero, Lozana atiende cuidadosamente a su "territorio", la ciudad de Roma: "no hera venida, quando sabía toda Roma y cada cosa por estenso, sacava dechados de cada muger y ombre, y quería saber su vivir, y cómo y en qué manera" (pág. 100); "notava lo que le parescía a ella que le avía de aprovechar para ser sienpre libre y no sujeta a ninguno..." (pág. 18).

Este afán de independencia es su idea fija. Ya que no ha nacido "hija de algo", ya que carece de árbol genealógico, se propone ser "hija de sus obras", hechura de sí misma. Por eso trata de evitar complicaciones "con casadas ni con virgos". Prefiere que las prostitutas y otra "gente ruin" la hayan menester a ella, y no ella a ellos (pág. 130). Por eso pone tienda de alcahueta y no de prostituta.

Todos sus talentos se ponen al servicio de esta busca de independencia y autonomía. Entre ellos, el principal es su don de gentes. Al comienzo de su estancia en Roma, asombra a Teresa con su mimetismo: "Con los cristianos será cristiana, y con los jodíos jodía, y con los turcos turca, y con los hidalgos hidalga, y con los ginoveses ginovesa, y con los franceses francesa, que para todos tiene salida" (págs. 30-31). Posee la cualidad por excelencia del experto hombre de negocios: "[a] cada uno nonbra por su nonbre" (pág. 100). Su soltura de lengua - no palabrería sin objeto, sino tremendo poder de persuasión bajo ese disfraz- provoca la admiración de todos sus vecinos. Beatriz, la primera vez que se encuentra con ella, no puede menos de exclamar: “'Avéys visto? ¿Qué lengua, qué saber!” (pág. 
3o). Porque Lozana no sólo habla de manera persuasiva, sino también con inteligencia. Gracias a este "saber", producto de su "ingenio", es posible su labia y su capacidad de persuasión. El "ingenio mirable" 12 de Lozana es un don especial de la naturaleza: "a la señora Aldonça no le faltava nada, que sin maestro tenía ingenio y saber, y notava las cosas mínimas por saber y entender las grandes y arduas" (pág. 14). Ella misma se siente orgullosa de sus dotes naturales; no pierde oportunidad de llamar la atención sobre su inteligencia: "Yo sé muncho; si agora no me ayudo en que sepan todos mi saber, será ninguno" (págs. 17-18). Con este despliegue y uso de sus talentos, Lozana ejerce una influencia inaudita sobre la ciudad de Roma y saca pingües ganancias.

Lozana es lo que es porque la naturaleza la ha dotado generosamente, y porque no hay escrúpulos de ninguna índole que emboten los ímpetus de esa criatura de la naturaleza. Su exuberencia, su viveza, su desenvoltura, en una palabra, su "lozanía", cualidades de una jaca de pura sangre ${ }^{1:}$, son los rasgos más salientes de su carácter. Todas las españolas de Roma, dice Delicado, son "lozanas", pero Aldonza la de Córdoba opaca a las demás: "Dios se lo avía puesto en su formación” (pág. 16). Esta suprema lozanía contribuye muchísimo a su éxito material, pues nadie que la conociera hablaba de otra cosa: "Era dicho entre todos de su loçanía, ansí en la cara como en todos sus mienbros. Y viendo que esta loçanía era de su natural, quedóles en fábula, que ya no entendían por su nonbre Aldonça, salvo la Loçana" (pág. 14).

Así, esta Lozana fué una versión femenina de Cellini, una criatura de la naturaleza, dinámica y sin escrúpulos, en una Italia renacentista aún no sacada de su embriaguez por el Saco de Roma. Cellini y Lozana son dos síntomas de la grandeza y miseria, de la vitalidad y perversión de Roma hacia 1525 . Y Delicado pasa del síntoma a la enfermedad.

El fondo en que Lozana se levanta a la prosperidad no es la Roma santa, la Ciudad Eterna, sino la Roma putana, la Roma meretrice. Al llegar a la ciudad en $15^{1} 3^{14}$, la española presencia la pomposa coronación de León X. Este episodio es el único indicio de que los hechos contados en el Retrato se desarrollan en las cercanías de la basílica de San Pedro. Después de él, Roma se pre-

${ }^{12}$ Pág. 1; y cf. pág. 18: "Ella tenía gran ver e ingenio diabólico y gran conoscer, y en ver un ombre sabía quánto valía, y qué tenía, y qué la podía dar, y qué le podía ella sacar".

13 Véase Covarkubias, Tesoro, Madrid, 1611 , s. v. Logano: "Cauallo loçano, el que se huella con gallardía. Logania, aquella gallardía y despejo".

1: Menf́ndez Pelayo, sin ninguna otra prueba, da por sentado que "toda la acción de la Lozana pasa en 1513 " (op. cit., pág. xcxi, nota 2). 
senta, no como centro de la cristiandad, sino como pozo de maldades, como la ciudad de total corrupción.

La técnica del autor, como hemos dicho, consiste en pintar el detalle para retratar el todo, en pintar a Lozana para retratar a Roma. La Lozana andaluza se nos presenta como un intento de describir toda una comunidad, una comunidad en extremo solidaria, en que cada ciudadano es miembro de otro: cada uno participa en cierto modo de la culpa y también de la gloria de la ciudad. Todos, fatalmente, tienen su responsabilidad por la podredumbre de Roma, que, al igual que Sodoma y Gomorra, envuelve en su pecado a sus habitantes, nativos o forasteros. Romanos por nacimiento, italianos de otras ciudades y extranjeros residentes en Roma, todos por igual se desentienden del pecado: "en Roma todo passa sin cargo de conciencia" (pág. 125). Clérigos y laicos reconocen su culpabilidad, y luego la olvidan. La ciudad de Roma se ha adueñado de cuantos viven en ella. Es preciso purificar a la ciudad, como entidad corporativa, para luego limpiar de sus pecados a los individuos que la integran. Los individuos, arrastrados por el ambiente, son incapaces de tener buenas costumbres; ni un santo lograría preservar allí su virtud. Así, para retratar la vida corporativa de la ciudad, el autor presenta una gran variedad de figuras; todas ellas vuelven la vista hacia Lozana, núcleo artístico, cuasi-alegórico, de la Roma meretrice. Esa muchedumbre de personajes forma el cuadro de la Roma anterior al Saco; todos justifican el relajamiento de su vida con un "así lo hacen todos". La ciudad atrae como imán a las prostitutas de todo el mundo: "¿Qué quiere dezir que vienen tantas a ser putas a Roma?", pregunta Lozana al Balijero; y éste responde: "Vienen al sabor y al olor; de Alemania son traýdas, y de Francia son venidas. Las dueñas d'España vienen en romeaje, y de Ytalia vienen con carruaje" (págs. 88-89). Pero al mismo tiempo, con su habilidad de posesión demoníaca, la ciudad empuja al pecado a todos cuantos atrae. Ésta es la Roma proverbial: a la tierra do fueres...; "en Roma, como en Roma". Ésta es la Roma del tradicional apodo: "Es la mayor parte de Roma burdel, y le dizen Roma putana" (pág. 4o).

Lo que reúne en un todo las distintas partes del cuadro es una idea de culpa colectiva, idea de gran antigüedad, por más que repugne al pensamiento liberal de hoy ${ }^{15}$. La actitud de Delicado se ve claramente en la charla de Lozana con una granadina. Lozana reprueba el que su compatriota no siga la corriente; la granadina se siente tentada a hacerse amiga de un hombre que ya se ha acostado con su hija: "mas porque se echó con mi hija, no quise pecar

${ }^{15}$ Sin embargo, el concepto de culpa colectiva reapareció durante la última guerra y en los juicios que a ella siguieron. 
dos vezes", a lo cual replica Lozana: "No seríades vos la primera qu'esso haze en Roma sin temor. ¡Tantos ducados tuviéssedes! ...Perdéys lo mejor de vuestra vida. ¿Qué! ¿Pensáys que estáys en Granada, do se haze por amor?" (págs. 125-126). De este modo, el autor hace constar su idea de la culpa colectiva: en Roma los pecadores olvidan sus escrúpulos por hacer lo que hacen los romanos.

Pero Roma no es sólo una ciudad de prostitutas, sino también una ciudad de "Iibertad", esto es, de libertinaje. EI exceso de libertad causa el relajamiento o desaparición de los criterios morales, determina una confusión total. Los extranjeros no son sino un elemento más en el caos. Las mujeres se corrompen ante todo por ese exceso de libertad: "es tanta la libertad que tienen las mugeres, que ellas los buscan [y] llaman, porque se les ronpió el velo de la honestidad" (pág. 85).

Roma -licenciosa, impúdica, atractiva, pecadora- es, pues, una sembradora de corrupción: "por esso se dize: Roma, triunfo de grandes señores, paraýso de putanas, purgatorio de jóvenes, ynfierno de todos, fatiga de bestias, engaño de pobres, peciguería de vellacos" (pág. 6o). La corrupción y el soborno son la ley para las autoridades civiles y eclesiásticas. En algún lugar aparece una prostituta famosa por ser "favorida de un perlado" (pág. 38). Y las cortesanas tienen que pagar tributo a los capitanes de la justicia (pág. 39).

Podría perdonarse tanta maldad si no fuese por el vicio de la complacencia, y aun cinismo, que agrava todos los demás vicios. Cuando Lozana pregunta qué cosa dice cierto orador callejero, Rampín le da esta respuesta: "Predica cómo se tiene de perder Roma, y destruirse el año del xxvir, mas dízelo burlando" (pág. 6o). Los pecadores sienten la amenaza del cielo, pero la toman a burla. El castigo será apocalíptico; habrá que huir de él, pues nadie podrá mirarlo cara a cara ni luchar:

Autor-Pues año de veynte e siete, dexa a Roma y vete.

ConPañero- ¿Por qué?

Autor-Porque será confusión y castigo de lo pasado.

Conpañero-A huir quien más pudiere.

Autor-Pensá que llorarán los barbudos, y mendicarán los ricos, y padescerán los susur[r]ones, y quemarán los públicos y aprobados y canonizados ladrones (págs. 108-109).

Todos a una están condenados, ya que cada uno es miembro del otro. A culpa colectiva, castigo colectivo. Pero los más culpables -Delicado insiste en ello- son los miembros de la jerarquía eclesiástica. Si éstos hubiesen dado mejor ejemplo a la ciudad, habrían podido evitarse los padecimientos comunes. Por su orgullo (el primer pecado del hombre), los prelados son la cabeza de esa sociedad 
pecadora; y en su destrucción arrastrarán a los pecadores más menudos:

\author{
RANPín-Los cardenales son aquí como los mamellucos. \\ LoçANA-Aquéllos se hazen adorar. \\ RANPÍN-Y éstos también. \\ LOÇANA-Gran sobervia llevan. \\ RANPÍN-El año de veinte y siete me lo dirán. \\ LOÇANA-Por ellos padeceremos todos (pág. $3^{8}$ ).
}

En la pintura de la corrupción de Roma no podía faltar la Iglesia. Ciertamente, Delicado, con mucha prudencia, afirma no haber dicho nada tocante a la religión o a la Iglesia: da a las secciones de su libro el nombre de "mamotretos"16, porque "capítulo" es palabra consagrada por la Biblia, y, continúa, "en todo este Retrato no ay cosa ninguna que hable de religiosos, ni de santidad, ni con yglesias, ni eclesiásticos, ni otras cossas que se hazen que no son de dezir" (pág. 270). Pero, como hemos visto, esto no es del todo cierto, aunque tampoco es una mentira descarada. La Iglesia no tiene en efecto sino un papel secundario; hay en la obra varios clérigos glotones o lascivos, y un fraile refitolero que paga sus visitas a Lozana con las provisiones que le dan para el convento, pero son pocos los eclesiásticos de esta clase, y sólo indirectamente se alude a su participación en el pecado colectivo de Roma.

En resumen, la Lozana andaluza es un hábil intento de pintar el retrato literario ${ }^{17}$ de una mujer que encarna la vitalidad y la degradación de la Italia renacentista, y, a través de ella, un cuadro

10 José Sánchzz estudia el empleo de la palabra mamotreto en su artículo "Nombres que reemplazan a capitulo en libros antiguos", HR, XI, 1943, pág. 157: "Según el Diccionario de Autoridades, la palabra mamotreto es "el libro o quaderno que sirve para apuntar y anotar las cosas que se necesitan tener presentes para ordenarlas después'. También puede ser un libro o legajo muy abultado, principalmente cuando es irregular y deforme. Se recordará que La Lozana andaluza está en forma dialogada y que intervienen ciento veinticinco personajes, lo que produce alguna confusión; el ambiente es semiitaliano, semiespañol, y contiene elementos folklóricos, históricos, supersticiones, noticias de cocina; hay cuentos interpolados; se habla español, italiano y catalán; es decir, de estructura irregular, el libro es un verdadero "mamotreto"." El autor de la Lozana da una explicación parecida: "Quiere decir mamotreto libro que contiene diversas razones o conpilaciones ayuntadas. Ansimismo porque en semejantes obras seculares no se deve poner nonbre ni palabra que se apertenga a los libros de sana y santa doctrina" (pág. 270). Una prueba de que su empleo de la palabra era arbitrario y artificial la tenemos en sus numerosos olvidos (cf. pág. 67: "Estando escriviendo el pasado capítulo ...").

${ }^{17}$ Es lástima que Renssezafr W. Lee, en su excelente contribución a la historia de las ideas, "Ut pictura poesis: the humanistic theory of painting" (en The Art Bulletin, XXII, 1940, págs. 197-269), no haya descubierto ninguna teoria humanística sobre la relación entre retrato y novela. 
de Roma en el momento más corrompido de su historia. El autor, artista consciente de sí mismo y de lo que lo rodea, se sirve de una técnica sumamente original: la reproducción exacta, por medio del diálogo, de los fenómenos que ha observado. Puede que la Lozana andaluza haya tenido poca importancia en el desarrollo de la novela española; pero posee por sí misma el mérito de ser un importante experimento artístico.

The Johns Hopkins University.

BRUCE W. WARDROPPER 